\title{
Preparation and characterization of large format macroporous cryogel discs for use in affinity chromatography and biotechnological applications.
}

\author{
Wim Noppe 1*, Roxanne Cordier1, Pieter Baatsen2 and Hans Deckmyn1,3 \\ 1 KU Leuven Campus Kortrijk, IRF Life Sciences, E. Sabbelaan 53, B-8500 Kortrijk, \\ Belgium \\ ${ }_{2} \mathrm{KU}$ Leuven, Department of Neurosciences, Electron Microscopy Platform \& Bio \\ Imaging Core, VIB - KU Leuven Center for Brain \& Disease Research, O\&N4 \\ Herestraat 49 , B-3000 Leuven, Belgium \\ ${ }_{3} \mathrm{KU}$ Leuven Campus Kortrijk, Laboratory for Thrombosis Research, E. Sabbelaan 53, \\ B-8500 Kortrijk, Belgium
}

${ }^{*}$ Corresponding author

Wim Noppe

Email: wim.noppe@kuleuven.be

phone: +32-56-246418

\begin{abstract}
We have prepared and evaluated larger format phage-bound epoxy-cryogel columns in order to increase the yield of bound target. Freezing thermograms showed that larger column formats $(2,5 \mathrm{~cm}-5 \mathrm{~cm}$ diameter) are not usable due to irregular polymerization phenomena. Preparing thin discs of $0,5 \mathrm{~cm}$ height with similar diameter proved to be an excellent alternative. Discs could be stacked and run in a chromatographic set up. In this way we could increase the matrix volume, ligand binding capacity and finally the yield of bound target. By increasing the column volume about 7 fold, we observed a twelve fold increase of ligand density and a 7 fold increase in the yield of protein recovery in a column where phages were attached without spacer and a 10 to 34 fold increase in a spacer column, depending on the spacer used.
\end{abstract}

\section{Keywords}

Cryogel disc, peptide-displaying phage ligand, affinity chromatography 


\section{Introduction}

Supermacroporous cryogels are a novel generation of chromatographic stationary phases that can be used for purification of particulate containing feed stocks without prior steps in the down-stream processing [1,2]. The supermacroporous structures with interconnected pores of up to $100 \mu \mathrm{m}$ allow purification of materials from different size without risk of clogging the matrix. Very small molecules, e.g. metals, toxins, hormones, up to larger structures such as proteins, plasmids, viruses and even intact cells can be processed on the cryogel columns. Due to the big pore structures inside the gel also high flow rates can be applied such that large batches of sample can be processed in a reasonable time frame. Next to these structural advantages, cryogels are low cost and can be readily prepared in different formats such as monolithic columns, thin sheets, beads or discs. Big pore structures inside the cryogel however also means that only a small amount of polymer, $3-4 \%$ of the total volume [3] is available for anchoring ligands. This has a direct influence on the binding capacity of such columns. Preparing larger sized monolithic columns is not straightforward due to restrictions correlated to the cryopolymerization procedure. Cryo-polymerization is highly dependent on the freezing temperature. The temperature should be as constant a possible over the whole gel to insure equal freezing over the whole gel. By preparing larger column formats, a difference in the freezing temperature is observed as shown by the freezing thermograms, resulting in uneven formation of pores. To deal with this problem we focused on the preparation of monolith sheets/discs instead of columns. The sheets are casted in a glass mold and after polymerization discs are cut out. Discs are prepared with diameters varying from $0.5 \mathrm{~cm}$ diameter $(\varnothing)$ up to $1.2 \mathrm{~cm} \varnothing$. Discs made of poly(2-hydroxyethyl methacrylate) (pHEMA) have been used with different protein ligands in the range of $0.5 \mathrm{~cm} \varnothing$ to $1.2 \mathrm{~cm} \varnothing$ : e.g. IgG was purified from human plasma on a $0.5 \mathrm{~cm} \varnothing$ thiophilic pHEMA cryogel disk [4] or proteins could be purified by $0.8 \mathrm{~cm} \varnothing-2.5 \mathrm{~cm} \varnothing$ pHEMA cryogel discs with reactive dye ligands [5,6] but also plasmid DNA was purified on $0.8 \mathrm{~cm} \varnothing-1 \mathrm{~cm} \varnothing \mathrm{pHEMA}$ cryogel discs with different coupled ligands $[7,8]$. Apart from biological materials described above, also metals could be recovered on cryogel discs. Cadmium was recovered on a $0.8 \mathrm{~cm} \varnothing$ reactive dye-pHEMA cryogel disc [9] while uraniumoxide was trapped on a $1 \mathrm{~cm} \varnothing$ glutamic acid-pHEMA cryogel disc [10]. Acrylamide cryogel discs $(\varnothing= \pm 2.4 \mathrm{~cm})$ have been successfully used for the continuous production of monoclonal antibodies from a hybridoma cell culture which grows in the discs [11].

In the present work we have focused on the preparation and characterization of polyacrylamide-epoxy based cryogel discs with an $\geq 2.5 \mathrm{~cm} \varnothing$. Discs with different acrylamide concentrations were made and compared in function of ligand binding and target binding capacity. As in earlier work [12] we determined the beneficial effect on the yield using spacers to immobilize selected phage, we here will combine upscaling the column format by using larger discs columns in combination with the introduction of spacers to obtain a higher ligand binding allowing to further optimize the yield of the target of interest. 


\section{Materials and Methods}

\section{Materials}

Allyl glycidyl ether, iminodiacetic acid and 1,6-diamino hexane were purchased from Sigma-Aldrich (Bornem, Belgium); acrylamide, methylene-bis-acrylamide, TEMED, ammonium persulfate, glutaraldehyde, ethanolamine and iminodiacetic acid (IDA) were from Sigma (St.Louis, Mo); C10/10, XK16/20, XK26/20, XK50/20 columns and Äkta Pure chromatographic system are from GE Healthcare (Uppsala, Sweden);

Vernier stainless steel temperature probe and Logger Pro software are from Vernier (Beaverton, OR).

\section{Experimental methods}

\section{Preparation of Epoxy-cryogel by cryogenic polymerization}

Epoxy-cryogel columns with a total monomer concentration of $6 \%$ or $7,5 \%$ are prepared according to published protocols [13]. Briefly, acrylamide (Aam) and methylene-bis-acrylamide (Bis-Aam) are mixed in a molar ratio of Aam/Bis-Aam= 5 . Allyl glycidylether (AGE), providing reactive epoxy groups, is added to Aam/AGE in a molar ratio of 10 to obtain a cryogel with available epoxy groups for further coupling strategies. A 10\% ammonium persulfate (APS) solution in water and TEMED in a final concentration of respectively $1 \%(\mathrm{~V} / \mathrm{V})$ and $0,156 \%(\mathrm{~V} / \mathrm{V})$ are added to the mixture. The polymer mixture is poured in different column formats (GE Healthcare, Uppsala, Sweden) and polymerized at $-12^{\circ} \mathrm{C}$ for 20 hours. After polymerization the columns are thawed at RT and extensively washed with MilliQ-water (MQ-water) to remove all nonpolymerized material. Cryogel discs are prepared in similar conditions as above by pouring the polymer mixture in a glass mold ( $5 \mathrm{~mm}$ spacer). After polymerization and thawing the cryogel was cut in circular discs, $2.6 \mathrm{~cm}$ or $5 \mathrm{~cm} \varnothing$. The discs are extensively washed with MQ-water and stacked in a column with corresponding diameter.

\section{Preparation of iminodiacetate-cryogel}

To determine the ligand density, iminodiacetic-cryogels (IDA-cryogel) are prepared [13]. Briefly, the epoxy-cryogel columns $(1 \mathrm{~cm}-1.6 \mathrm{~cm} \varnothing)$ are washed with $60 \mathrm{ml} 0.5 \mathrm{M}$ $\mathrm{Na}_{2} \mathrm{CO}_{3}$ followed by a wash with $60 \mathrm{ml} 1 \mathrm{M} \mathrm{Na}_{2} \mathrm{CO}_{3}$ both at $1 \mathrm{ml} / \mathrm{min}$. Next, $50 \mathrm{ml} 0.5 \mathrm{M}$ IDA in $1 \mathrm{M} \mathrm{Na} \mathrm{CO}_{3} \mathrm{pH}=9.6$ is recirculated over the column at $0.5 \mathrm{ml} / \mathrm{min}$ for 20 hours at RT. The column is washed with $60 \mathrm{ml} 1 \mathrm{M} \mathrm{Na} 2 \mathrm{CO}_{3}$ at $1 \mathrm{ml} / \mathrm{min}$ followed by extensive washing with $\mathrm{MQ}$-water until neutral $\mathrm{pH}$. In a similar way the stacked disk columns (2.6 $\mathrm{cm}-5 \mathrm{~cm} \varnothing$ ) are washed with respectively $90 \mathrm{ml} 0.5 \mathrm{M} \mathrm{Na} 2 \mathrm{CO}_{3}$ and $1 \mathrm{M} \mathrm{Na}_{2} \mathrm{CO}_{3}$ at 1 $\mathrm{ml} / \mathrm{min}$, followed by recirculation of $100 \mathrm{ml} 0.5 \mathrm{M}$ IDA in $1 \mathrm{M} \mathrm{Na} 2 \mathrm{CO}_{3} \mathrm{pH}=9.6$ at 0.5 $\mathrm{ml} / \mathrm{min}$ for 20 hours at RT. Then the disk column is washed with $90 \mathrm{ml} 1 \mathrm{M} \mathrm{Na}_{2} \mathrm{CO}_{3}$ at $1 \mathrm{ml} / \mathrm{min}$ followed by extensive washing with $\mathrm{MQ}$-water until neutral $\mathrm{pH}$. The columns are stored at $4^{\circ} \mathrm{C}$ until further use. 


\section{Thermograms}

The freezing profiles are recorded by placing 1 or 2 Vernier temperature probes at half height in the polymerization solution. Freezing is done at $-12^{\circ} \mathrm{C}$. Temperature changes are measured in function of time until the temperature reaches $\mathrm{T}_{f}$ (temperature set in the cryostat). A single probe was used for $1 \mathrm{~cm} \varnothing$ column and for the glass mold setup. Two probes were placed in the $2.6 \mathrm{~cm}$ and $5 \mathrm{~cm} \varnothing$ columns: the first one near the edge of the column and the second probe in the middle of the column. Data are recorded by LoggerPro software (Vernier).

\section{Scanning Electron Microscopy}

For Scanning Electron Microscopy, the polymerized discs were cut in wedges, exposing the surface from the center of the disc to the periphery (fig.2, view A), as well as the interior (fig.2, view B). The pieces were mounted on a $2.5 \mathrm{~cm}$ diameter SEM support stubs with carbon stickers and carefully applied silver paint. Subsequently, the samples were sputter coated with $10 \mathrm{~nm}$ chromium in a Leica ACE600 coating machine. Samples were observed and images taken with a Zeiss Sigma scanning electron microscope, operated at $5 \mathrm{kV}$ at high vacuum with a SE detector, or at reduced vacuum $(0.16 \mathrm{~Pa})$ with a VPSE detector, and a working distance of about $7 \mathrm{~mm}$.

\section{Determination of epoxy density on the cryogel}

The amount of available epoxy groups for ligand coupling, is determined according to Arvidsson et al. [13]. The epoxy-cryogel is washed with MQ-water and next saturated with a $0.5 \mathrm{M} \mathrm{CuSO} 0_{4}$ solution in water at $1 \mathrm{ml} / \mathrm{min}$ at $\mathrm{RT}$. Excess of $\mathrm{Cu}_{2+}$ is washed away with $\mathrm{MQ}$-water. Bound $\mathrm{Cu}_{2}+$ is then eluted with 0.1M EDTA $\mathrm{pH}=7.6$ and determined spectrophotometrically at $730 \mathrm{~nm}$. The Cu2+-EDTA complex has a $\varepsilon_{730}=46.8 \mathrm{M}-1 \mathrm{~cm}-1$.

\section{Phage coupling on epoxy-cryogel}

Filamentous M13-bacteriophages, clone HuN and HuL, are selected from phage display libraries for binding to human lactoferrin (HULF) as described earlier [14]. Phage coupling to the epoxy-column was done as described earlier [10]. Briefly, the epoxy-cryogel is washed with MQ-water at $1 \mathrm{ml} / \mathrm{min}$ followed by an equilibration step with $0.2 \mathrm{M} \mathrm{Na} \mathrm{CO}_{3}$ at $1 \mathrm{ml} / \mathrm{min}$. Next the phage solution in $0.2 \mathrm{M} \mathrm{Na}{ }_{2} \mathrm{CO}_{3}$ is recirculated over the column at $0.5 \mathrm{ml} / \mathrm{min}$ for 16 hours. After phage coupling the column is washed with $0.2 \mathrm{M} \mathrm{Na} \mathrm{CO}_{3}$ at $1 \mathrm{ml} / \mathrm{min}$ to remove unbound material. Next, the column is incubated with $0.1 \mathrm{M}$ ethanolamine in $0.2 \mathrm{M} \mathrm{Na}_{2} \mathrm{CO}_{3}$ at $0.5 \mathrm{ml} / \mathrm{min}$ for 3 hours to block all remaining free epoxy groups. Finally the column is extensively washed with phosphate buffered saline (PBS) until the $\mathrm{pH}=7.5$. All steps are performed at $\mathrm{RT}$. At this stage the column is ready to perform binding experiments and can be stored at $4^{\circ} \mathrm{C}$ until further use.

\section{Protein binding experiments}

The cryogels are housed in commercial available column hardware as mentioned in the materials section. We used columns from GE Healtcare such as C10/10, XK16/20, XK26/20 or XK50/20. These columns were optimal as they were easy the handle as they had the correct dimensions to prepare columns of different dimensions for chromatographic experiments. The epoxy-phage-cryogels are connected to an Äkta 
Pure system (GE Healthcare, Uppsala, Sweden) and equilibrated with PBS buffer. Defatted human milk is diluted twice with PBS and is loaded on the column and washed with PBS to remove unbound protein. The column is then eluted with phosphate buffer$1 \mathrm{M} \mathrm{NaCl} \mathrm{pH=7.5} \mathrm{(PB-1M).} \mathrm{The} \mathrm{eluted} \mathrm{protein} \mathrm{fractions} \mathrm{are} \mathrm{pooled} \mathrm{for} \mathrm{quantification.}$ See table 1 for running parameters. Protein concentration of the pooled PB-1M fraction is determined based on the Folin-Ciocalteus method [15]. The yield is finally expressed as $\mu \mathrm{g}$ bound protein.

\section{Results and Discussion}

\section{Epoxy-cryogel}

\section{Column structure}

Poly-acrylamide based cryogels are prepared by cryo-polymerization at $-12^{\circ} \mathrm{C}$. To introduce reactive groups, allyl-glycidylether (AGE) is added as additional monomer in the polymerization solution. As evaluated earlier [12] optimal structural conditions and optimal AGE concentrations are observed at a molar acrylamide/AGE ratio of 10 . These conditions are used for preparation of all further cryogel gels. Until now only 1 $\mathrm{cm} \varnothing$ cryogels have been prepared. In order to improve the low binding capacity inherent to these gels, we now prepared larger formats and evaluated them. In first instance, columns of $1.6 \mathrm{~cm} \varnothing, 2.6 \mathrm{~cm} \varnothing$ and $5 \mathrm{~cm} \varnothing$ were prepared and compared to the $1 \mathrm{~cm} \varnothing$ column. Freezing thermograms are recorded as we anticipated the occurrence of a temperature gradient during polymerization in the larger sized columns. If the freezing temperature is not constant over the overall column, differences in polymerization rate might influence the column structure and especially the pore size. In the $1 \mathrm{~cm} \varnothing$ column we placed 1 temperature probe in the middle of the column, while for the $2.6 \mathrm{~cm} \varnothing$ and $5 \mathrm{~cm} \varnothing$ column 2 probes are used, one near the edge of the column and 1 in the middle of the column. We could clearly see that, when the diameter of the column was increased, indeed a temperature gradient over the column diameter was observed (Fig. 1a.) in contrast what happens in the $1 \mathrm{~cm}$ column. After the crystallization is completed in the $1 \mathrm{~cm} \varnothing$ column, the temperature drops quickly to the fixed $\mathrm{T}_{\mathrm{f}}$ of $-12^{\circ} \mathrm{C}$ in accordance to earlier results $[16,17]$. For the 5 $\mathrm{cm} \varnothing$ column we see a clear difference between the edge and the middle of the column. At the edge of the column the temperature drops more quickly than in the middle of the column. This can affect the polymerization rate of the cryogel resulting in an irregular pore size pattern. As can be seen in figure 1c there indeed is a clear difference in pore size at the edges compared to the middle of the cryogel, with a regular polymerization at the edges, while in the middle an irregular polymerization is observed with big gaps in the cryogel. Similar results were observed by Savina et al. [18]. In order to overcome this, larger formats were prepared by polymerizing the cryogel in a $0.5 \mathrm{~cm}$ glass mold. This resulted in an even better thermogram as compared to the $1 \mathrm{~cm} \varnothing$ column (Fig. $1 b)$. The thinner the cryogel, the more even polymerization is observed over the whole gel. The pore structure of the cryogel discs was evaluated by scanning electron microscopy (Fig. 2), which showed equal pore size over the whole cryogel disk from periphery to the center of the disk. Also in depth the pore size is equally divided. No significant deterioration of the porous structure caused by drying the cryogel discs was observed by SEM or ESEM [19]. As we prepare cryogels by the same protocol as 
referred in previous paper we believe we can trust that the morphology we observed by SEM (fig. 2) is representative for the used material.

We next prepared and evaluated cryogel columns with 14 discs of $2.6 \mathrm{~cm} \varnothing$ stacked or 7 discs of $5 \mathrm{~cm} \varnothing$ stacked. During stacking a slight pressure is applied to obtain a good contact between the individual discs. The cryogels are highly elastic so the applied pressure has no influence on the separation profile as observed in earlier experiments (data not shown). Applying too high pressure on a classical bead column affects the packing showing negative effects in the separation profile or in the worst case collapse of the column.

\section{Epoxy density on the cryogel}

For all cryogel formats used, the molar ratio Aam/AGE=10. As such, an increase in epoxy groups therefore should be correlated to the volume of the cryogel and indeed the amount of available epoxy groups increased linearly with the column volume (Fig. 3 ) as expected. The column volumes used for a regular $1 \mathrm{~cm}$ and a $1.6 \mathrm{~cm} \varnothing$ column were respectively 5.5 and $11.5 \mathrm{ml}$. A $2.6 \mathrm{~cm} \varnothing$ disk column with 14 discs stacked has a column volume of $\pm 37 \mathrm{ml}$, the $5 \mathrm{~cm} \varnothing$ disk column with 7 discs a column volume of $\pm 69 \mathrm{ml}$. The $7,5 \%$ column volume of a $5 \mathrm{~cm} \varnothing$ disk column thus increased 12.5 fold as compared to a $1 \mathrm{~cm} \varnothing$ column and this was accompanied with an increase of \pm 244 $\mu \mathrm{mol}$ to $\pm 3020 \mu \mathrm{mol}$ epoxy respectively. A similar increase is observed for $6 \%$ columns with values from $\pm 200 \mu \mathrm{mol}$ to $\pm 2560 \mu \mathrm{mol}$ epoxy for respectively a $1 \mathrm{~cm} \varnothing$ and a $5 \mathrm{~cm}$ $\varnothing$ column. Increase of available epoxy content creates higher binding capacity for the phage ligand and ultimately a higher binding capacity for the target of interest resulting in a higher yield.

For further evaluation of the cryogel disk columns we worked with $7.5 \% 2,6 \mathrm{~cm} \varnothing$ disk columns with an epoxy content of $\pm 2000 \mu \mathrm{mol} /$ column (14 stacked discs). $5 \mathrm{~cm} \varnothing$ columns have indeed a higher epoxy content, but are harder to handle and to stack.

\section{Protein binding experiments}

\section{Influence of linear velocity}

Due to the high porosity of the cryogel, high linear velocities up to $750 \mathrm{~cm} / \mathrm{h}$ can be applied to the column with very low flow resistance $[20,21,22]$. However as the interaction between the phage ligand and the target can be categorized as a "pseudoaffinity" interaction, the target should stay long enough in the column to ensure good binding. Too high linear velocities thus should be avoided to achieve optimum binding conditions. We applied linear velocities between $\pm 5.5 \mathrm{~cm} / \mathrm{h}$ and $\pm 35 \mathrm{~cm} / \mathrm{h}$ (Fig. 4). A decrease of $\pm 10 \%$ in target binding capacity was observed when the linear velocity was increased up to $35 \mathrm{~cm} / \mathrm{h}$ as compared to $5.5 \mathrm{~cm} / \mathrm{h}$. For further experiments we set a fixed linear velocity of $22.5 \mathrm{~cm} / \mathrm{h}$ without losing substantial binding capacity.

\section{Binding experiments}

$2.6 \mathrm{~cm} \varnothing 14$ Disc columns were evaluated for binding capacity by varying the amount of phage ligand with or without introducing spacers. Phages were bound on the column at $1 \times 1010,1 \times 1011$ and $1 \times 10_{12}$ phage/ml in $65 \mathrm{ml}$ phage solution. Results show (fig. 5) that there is no marked increase in HuLF binding capacity when the phage concentration is increased from $1 \times 1010$ up to $1 \times 1012$ phages $/ \mathrm{ml}$ in a column without 
spacer.

The use of spacers in between the column and the phage increases the final yield of target binding (Noppe et al.,2017). We have prepared a $2.6 \mathrm{~cm} \varnothing 14$ disc column with a 1,6 diaminohexane $(1,6 \mathrm{dAH})$ or Lupasol FG spacer followed by coupling $65 \mathrm{ml}$ phage solution $(1 \times 1012$ phages $/ \mathrm{ml})$ similar to the columns described above. And indeed when running the same volume of milk sample on these stacked disc columns we observed an additional 2-10 fold increase of binding capacity depending on the spacer used. As the Lupasol FG spacer column showed the highest binding capacity we used this column to examine the binding saturation profile (fig. 5B). Results show that by loading a $50 \mathrm{ml}$ sample we reach the saturation point of the column. For this specific column we can finally elute $\pm 5.5 \mathrm{mg}$ of protein. In line with earlier results (Noppe et al.,2017) we found that the eluted protein has a purity of $90-95 \%$, meaning that we have eluted $\pm 5 \mathrm{mg}(= \pm 0.7 \mathrm{nmol})$ of pure human lactoferrin from the column. We have used $6,5 \times 10_{13}$ phages for coupling. When assuming that nearly all phages are coupled to the column as there is a vast excess of available coupling groups by using the branched spacer, we can expect \pm 0.55 nanomol peptide expressing p3 protein, which is defined as the ligand, available on the column. The amount of bound HuLF therefore would be in the same order as the amount of available ligand, which is in accordance with the experimental result showing column saturation in this set-up.

\section{Conclusion}

By upscaling from a $1 \mathrm{~cm} \varnothing$ non-spacer Hu5 phage column to a $2.6 \mathrm{~cm} \varnothing 14$ discLupasolFG-HuN phage column we observed a 70 fold increase in the binding yield by optimizing several column parameters such as choice of phage ligand, phage concentration for coupling, choice of spacer, sample volume and column volume. In order to increase the binding yield, we will further optimize the production of larger disc columns and more specific coupling procedures for the phage ligand.

Also, to the best of our knowledge, so far we are the first to introduce cryogels as chromatographic matrix in combination with peptide-expressing phages as affinity ligand in a chromatographic platform. In this paper we further optimized the platform (increasing capacity). In the way we believe that we could significantly improve our platform and that by this it can become useful in many more applications.

\section{Acknowledgements}

BASF Antwerp is greatly acknowledged for the gift of Lupasol FG 800. The research was supported by a grant from the KU Leuven Industrial Research Fund (C32/16/006).

\section{Conflict of interest}

The authors have declared no conflict of interest. 


\section{References}

1. Plieva F, Galaev IY, Mattiasson B. Macroporous gels prepared at subzero temperatures as novel materials for chromatography of particulate-containing fluids and cell culture applications. J. Sep. Sci. 2007; 30:1657-1671

2. Noppe W, Plieva F, Vanhoorelbeke K, Deckmyn H, Tuncel M, Tuncel A, Galaev IY, Mattiasson B. Macroporous monolithic gel, cryogels, with immonilized phages from phage-display library as a new platform for fast development of affinity adsorbent capable of target capture from crude feed stocks. J. Biotechnol. 2017;131:293-299. 3. Plieva F, Savina IN, Deraz S, Anderson J, Galaev IY, Mattiasson B. Characterization of supermacroporous monolithic polyacrylamide based matrices designed for chromatography of bioparticles. J. Chromatogr.B. 2004b; 807:129-137.

4. Bakhspour M, Bereli N, Senel S. Preparation and characterization of thiophilic cryogels with 2-mercaptoethanol as the ligand fir IgG purification. Colloids Surf. B. 2014; 113:261-268.

5. Percin I, Sener G, Demircelik AH, Bereli N, Denizli A. Comparison of two different reactive dye immobilized poly(hydroxyethyl methacrylate) cryogel discs for purification of lysozyme. Appl. Biochem. Biotechnol. 2015; 175:2795-2805.

6. Huseynli S, Baydemir G, Sari E, Elkak A, Denizli A. Affinity composite cryogel discs functionalized with Reactive Red 120 and Green HE 4BD dye ligands: Application on the separation of human immunoglobulin G subclasses. Mat. Sci. Eng. C. 2015; 46:7785.

7. Cimen D, Yilmaz F, Percin I, Türkmen D, Denizli A. Dye affinity cryogels for plasmid DNA purification. Mat. Sci. Eng. C. 2015; 56:318-324

8. Corman ME, Bereli N, Özkara S, Uzun L, Denizli A. Hydrophobic cryogels for DNA adsorption: effect of embedding of monosize microbeads into cryogel network on their adsorptive performances. Biomed. Chromatogr. 2013; 27:1524-1531.

9. Keles B, Inanan T, Tüzmen N, Denizli Cadmium removal performances of different dye ligands attached cryogel discs. Croat. Chem. Acta. 2015;88:139-149.

10. Bereli N, Türkmen D, Köse K, Denizli A. Glutamic acid containing supermacroporous poly(hydroxyethyl methacrylate) cryogel discs for $\mathrm{UO}_{2}+$ removal. Mater. Sci. Eng. C. 2015;56: 318-324.

11. Jain E, Karande AA, Kumar A. Supermacroporous polymer-based cryogel bioreactor for monoclonal antibody production in continuous culture using hybridoma cells. Biotechnol. Prog. 2010; 27: 170-180.

12. Noppe W, Deckmyn H. Development and screening of epoxy-spacer-phage cryogels for affinity chromatography: Enhancing the binding capacity. J. Sep. Sci. 2017; 40: 2575-2583.

13. Arvidsson P, Plieva F, Lozinsky VI, Galaev IY, Mattiasson B. Direct chromatographic capture of enzyme from crude homogenate using immobilized metal affinity chromatography on a continuous supermacroporous adsorbent. J. Chromatogr. A. 2003; 986:275-290.

14. Noppe W, Vanhoorelbeke K, Galaev IY, Mattiasson B, Deckmyn H. A probe for capture and Fe3+-induced conformational change of lactoferrin selected from phage displayed peptide libraries. J. Dairy Sci. 2004; 87: 3247-3255.

15. Lowry H, Rosebrough N, Farr A, Randall R. Protein measurement with the folin phenol reagent. J. Biol. Chem. 1951; 193: 265-275. 
16. Plieva F, Huiting X, Galaev IY, Bergenstahl B, Mattiasson B. Macroporous elastic polyacrylamide gels prepared at subzero temperatures: control of porous structure. $\mathrm{J}$ Mat. Chem. 2006; 16: 4065-4073.

17. Plieva F, De Seta E, Galaev IY, Mattiasson B. Macroporous elastic polyacrylamide monolith columns: processing under compression and scale-up. Sep. Purif. Technol. 2008; 65:110-116.

18. Savina I, Ingavle GC, Cundy AB, Mikhalovsky SV. A simple method for the production of large volume 3D macroporous hydrogels for advanced biotechnological, medical and environmental applications. Sci. Rep. 2016; 17: 21554.

19. Plieva F, Galaev IY, Mattiasson B. Macroporous gels prepared at subzero temperatures as novel materials for chromatography of particulate-containing fluids and cell culture applications. J. Sep. Sci. 2007; 30: 1657- 1671.

20. Persson P, Bayak O, Plieva F, Galaev IY, Mattiasson B, Nilsson B, Axelsson A. Characterization of a continuous supermacroporous monolithic matrix for chromatgraphic separation of large bioparticles. Biotechnol. Bioeng. 2004; 88: 224236.

21. Plieva F, Savina IN, Deraz S, Andersson J, Galaev IY, Mattiasson B. Characterization of supermacroporous monolithic polyacrylamide baseda matrices designed for chromatography of bioparticles. J. Chromatogr. B. 2004; 807:129-137. 22. Arvidsson P, Plieva F, Savina IN, Lozinsky VI, Fexby S, Bülow L, Galaev IY, Mattiasson B. Chromatography of microbial cells using continuous supermacroprous affinity and ion-exchange columns. J. Chromatogr. A. 2002; 977: 27-38.

\section{Legends}

Fig. 1 Freezing thermograms of different column/plate formats

(A) $1 \mathrm{~cm} \varnothing$ column (red); $2.6 \mathrm{~cm} \varnothing$ column-edge (black); $2.6 \mathrm{~cm} \varnothing$ column-middle (blue); $5 \mathrm{~cm} \varnothing$ column-edge (green); $5 \mathrm{~cm} \varnothing$ column-middle (grey). (B) $1 \mathrm{~cm} \varnothing$ column (red); $0,5 \mathrm{~cm}$ plate mold (blue). (C) A cross-cut of a $5 \mathrm{~cm} \varnothing$ column: red arrows shows big irregular pores in the middle of the column due to uneven polymerization caused by the temperature gradient over the column during freezing.

Fig. 2 SEM pictures of disc cryogels

SEM pictures taken from above and the side of a cryogel discs according to the attached profile of the pictures show a comparable pore structure. The stereo picture gives an idea of the tridimensional structure of the cryogel (can be seen by using stereo glasses). Below are pictures of different formats of cryogels: below left: $1 \mathrm{~cm}$ and 1.6 $\mathrm{cm}$ column format; below right: $1 \mathrm{~cm} ; 2.6 \mathrm{~cm}$ and $5 \mathrm{~cm} \varnothing$ cryogel discs.

Fig. 3 Epoxy concentration in cryogel discs [epoxy] in cryogels is measured by $\mathrm{Cu}^{2+-b i n d i n g ~ o f ~ d i f f e r e n t ~ c o l u m n / d i s c s ~ f o r m a t s . ~}$ [epoxy] is correlated to the column volume and \% of monomer in the cryogel. A 6\% monomer column (black) and a $7.5 \%$ column (red). The epoxy amount is expressed as $\mu \mathrm{mol}$ epoxy \pm SEM $(n=3)$

Fig. 4 Amount of bound protein at different flow rates.

On a HuL phage $2.6 \mathrm{~cm} \varnothing$ disk column (14 discs), two $\mathrm{ml}$ of human milk sample was 
applied at different flow rates. Bound protein was recovered and measured based on the Folin-Ciocalteus method. The amount of protein is expressed in $\mu \mathrm{g}$ bound protein $\pm \operatorname{SEM}(n=3)$.

Fig. 5 Binding capacity of phage column

(A) Similar $2.6 \mathrm{~cm} \varnothing$ epoxy-phage disc columns (14 discs) were prepared by coupling different amounts of HuN phage clone with or without spacer. All columns were run at $2 \mathrm{ml} / \mathrm{min}$ and different volumes of human milk sample are applied. $2 \mathrm{ml}$ (yellow bar); 5 $\mathrm{ml}$ (blue bar); $10 \mathrm{ml}$ (red bar) and $50 \mathrm{ml}$ (green bar) of human milk sample were applied. The spacers used are Lupasol FG (100a, branched spacer) and 1,6 diaminohexane (100b, linear spacer). The amount of protein bound is expressed as $\mu \mathrm{g}$ bound protein (mean, $n=3$ ). (B) Saturation profile of bound protein on a Lupasol FG -HuN disc column (100a) in function of the applied sample volume (mean \pm SEM, $n=3$ ).

Table 1 Chromatographic running parameters

All samples are run in three fold on Äkta Pure (GE Healthcare) under similar conditions as shown in table1. 
a

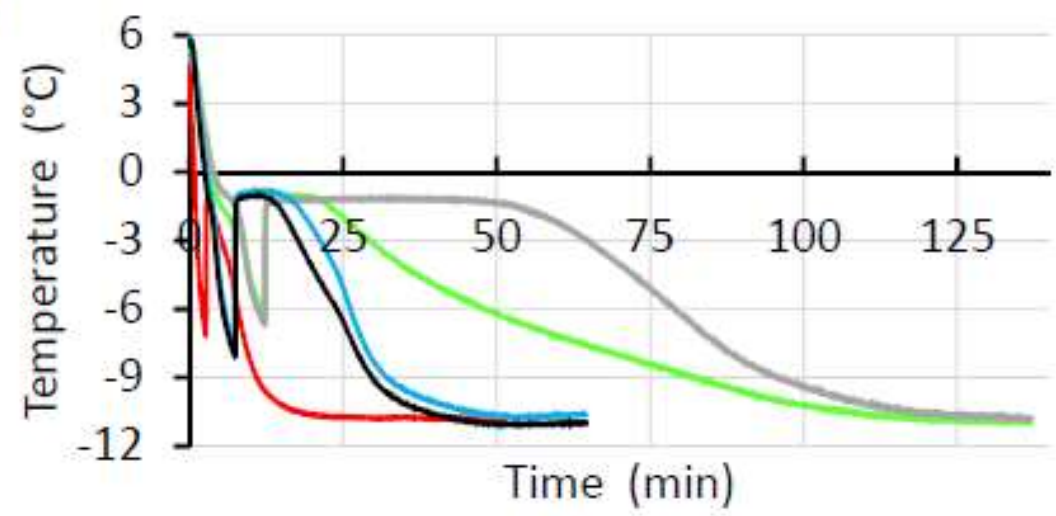

b

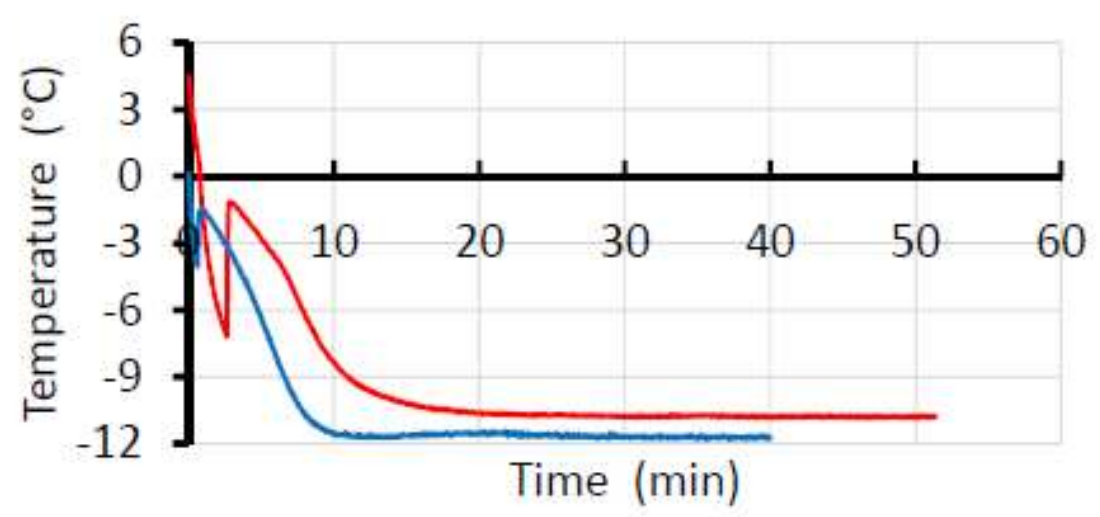

q

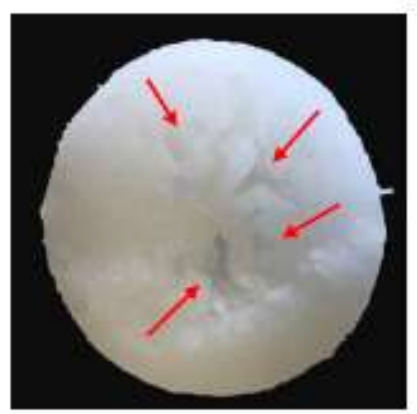


Figure 2.

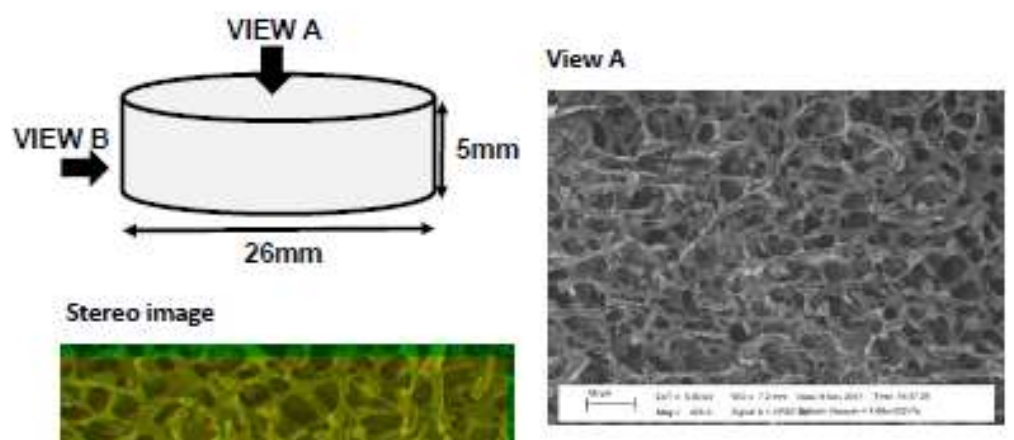

View B
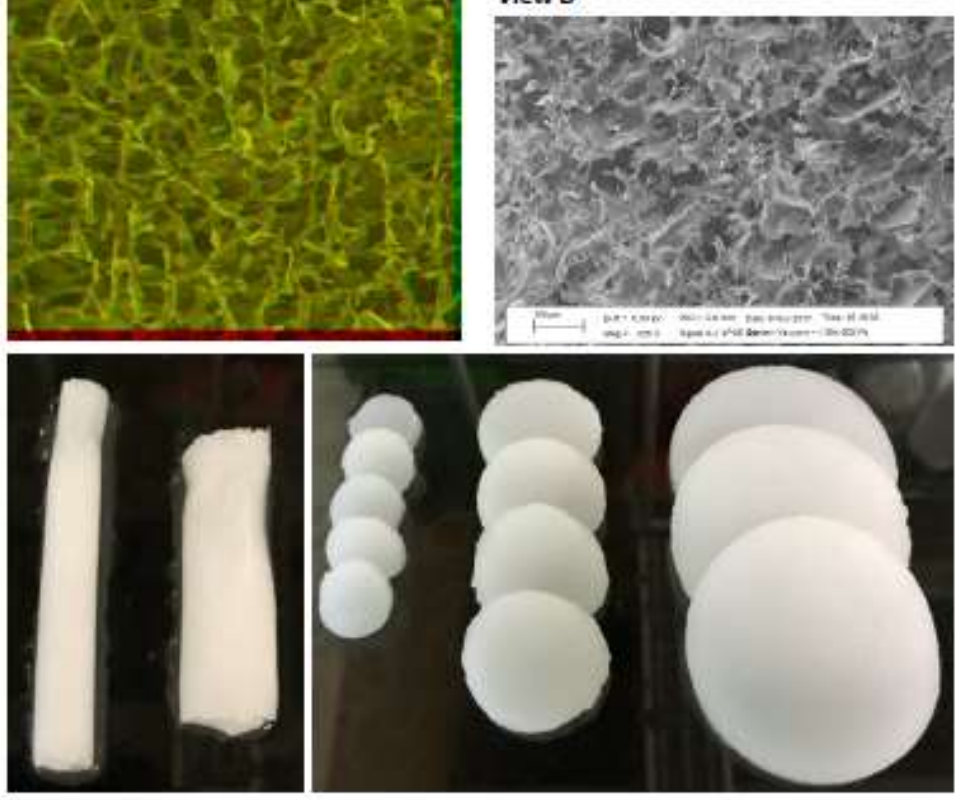
Figure 3

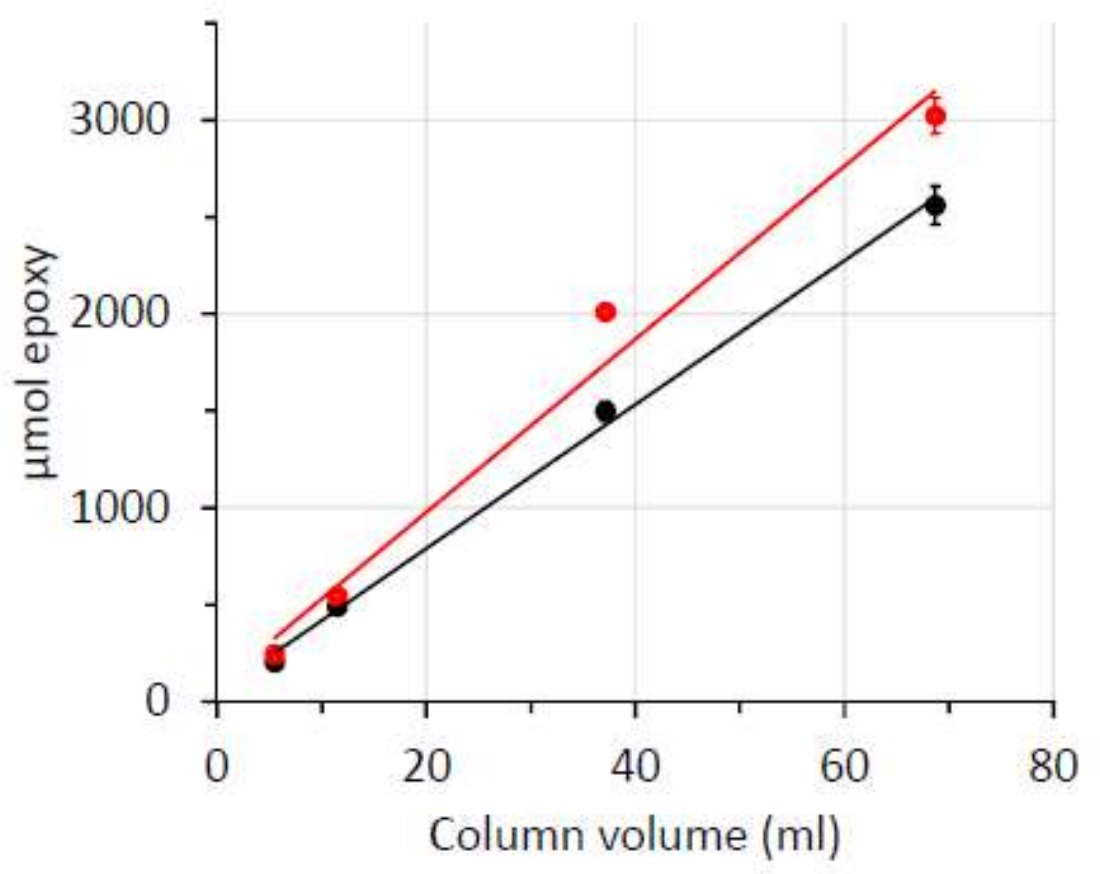


Figure 4 .

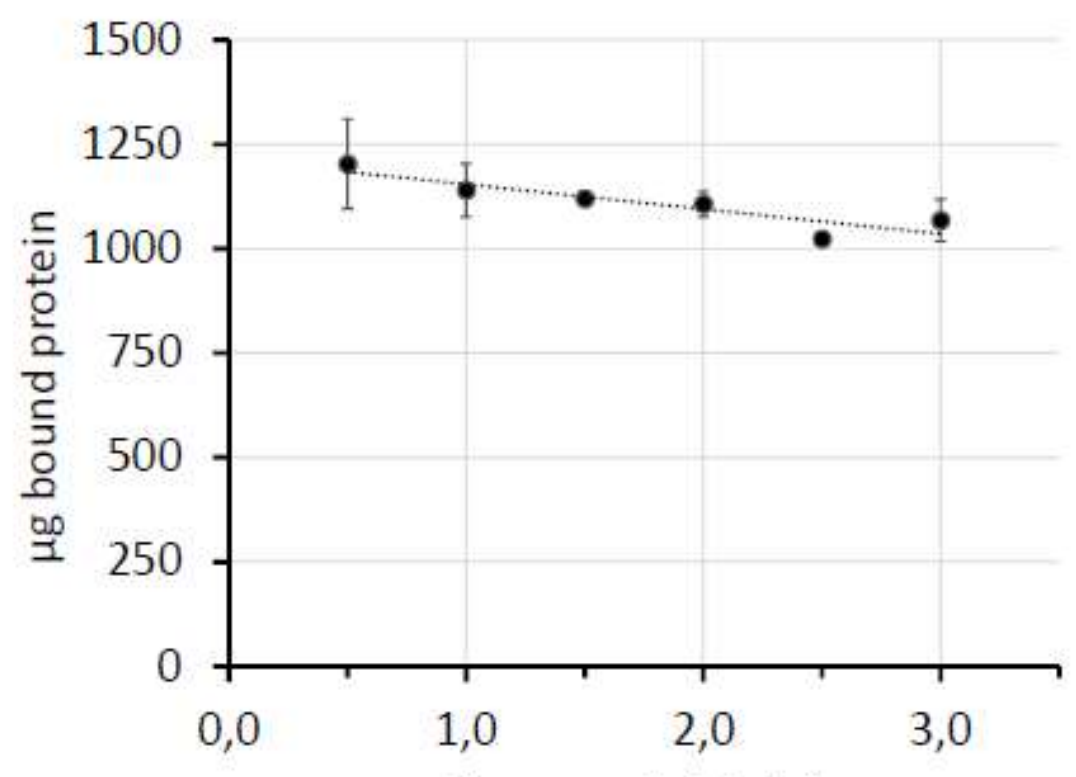

Flow rate $(\mathrm{ml} / \mathrm{min})$ 
Figure 5.

a
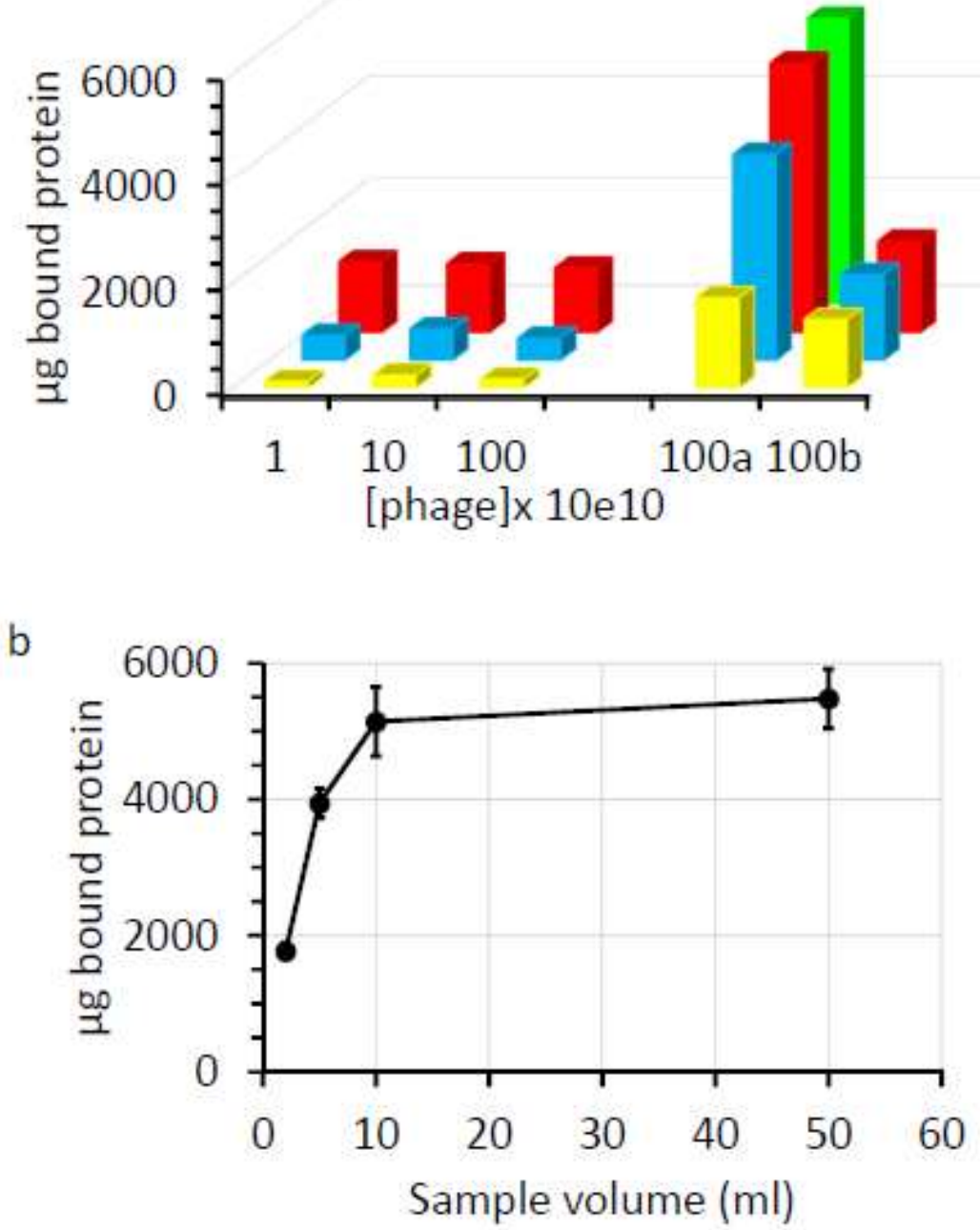

Table 1: Äkta running parameters

\begin{tabular}{|l|l|l|l|l|l|l|}
\hline STEP & $\begin{array}{l}\text { Flow } \\
\text { rate } \\
(\mathrm{ml} / \mathrm{min})\end{array}$ & Time & $\begin{array}{l}\text { Sample } \\
\text { Volume }\end{array}$ & $\begin{array}{l}\text { (min } \\
(\mathrm{ml})\end{array}$ & $\% \mathrm{~B}$ & $\begin{array}{l}\text { Fraction } \\
\text { size } \\
(\mathrm{min})\end{array}$ \\
\hline $\begin{array}{l}\text { Column } \\
\text { Equilibration }\end{array}$ & 2 & 5 & - & 100 & 0 & - \\
\hline $\begin{array}{l}\text { Sample } \\
\text { application }\end{array}$ & 2 & & $\begin{array}{l}2 / 5 / 10 / \\
50\end{array}$ & 100 & 0 & - \\
\hline $\begin{array}{l}\text { Column } \\
\text { wash }\end{array}$ & 2 & 45 & - & 100 & 0 & - \\
\hline Elution & 2 & 40 & - & 0 & 100 & 1 \\
\hline $\begin{array}{l}\text { Column } \\
\text { wash }\end{array}$ & 2 & 60 & - & 100 & 0 & - \\
\hline
\end{tabular}

